\title{
0 analiză intermediară a formelor medii şi severe de COVID-19 tratate în Clinica de Boli Infecțioase Craiova
}

\section{Lucian Giubelan, Livia Dragonu, Andreea Cristina Stoian, Florentina Dumitrescu}

\author{
Clinica de Boli Infecţioase, Universitatea de Medicină şi Farmacie, Craiova, România
}

\begin{abstract}
REZUMAT
Obiective. Descrierea şi diferenţierea formelor medii şi severe de COVID-19 diagnosticate şi tratate în Clinica de Boli Infecţioase Craiova (din cadrul Spitalului de Boli Infecţioase şi Pneumoftiziologie "Victor Babeş").

Material şi metodă. Studiu retrospectiv (martie 2020 - iulie 2020) al primele 300 de cazuri internate ce compară formele medii şi severe de COVID-19 din punct de vedere clinic şi biologic.

Rezultate. Au fost înregistrate 56 de cazuri medii şi 33 severe; între acestea, se înregistrează o serie de diferenţe cu semnificaţie statistică: vârsta pacienţilor $(49,5 \pm 16,13, p<0,0001)$, numărul de pacienţi obezi (12 vs. $14, p=0,06$ ), cu suferinţe cardiovasculare ( 8 vs. $18, p<0,0001)$, diabet zaharat ( 9 vs. 15 , $p=0,005)$ sau neoplazii (2 vs. $7, p=0,02)$. Mai mulţi pacienţi cu forme severe prezintă dispnee $(14$ vs. 24 , $p<0,0001)$, raluri pulmonare (8 vs. $13, p=0,01)$, valori crescute ale tensiunii arteriale sistolice $(2$ vs. 9 , $p=0,01)$, comă (0 vs. $5, p=0,01)$ sau imagine radiologică de tip bronhopneumonie $(0$ vs. $6, p=0,004)$. Bolnavii critici au un număr mai mare de leucocite $(6.176,07 \pm 2.512,05$ vs. $8.666,67 \pm 4.565,88, p=0,01)$, VSH la 1 oră mai mare $(43,05 \pm 18,09$ vs. $71,18 \pm 30,8 \mathrm{~mm}, \mathrm{p}<0,0001)$, nivel mai mare al proteinei $\mathrm{C}$ reactive $(29,62 \pm 19,81$ vs. $43,46 \pm 18,01 \mathrm{mg} / \mathrm{l}, \mathrm{p}=0,01)$, lactatului seric $(1,19 \pm 0,91 \mathrm{vs} .3,47 \mathrm{vs} 3,84 \mathrm{mEq} / \mathrm{l}, \mathrm{p}=0,006)$, glicemiei $(112,5 \pm 25,01$ vs. $304,45 \pm 273,58 \mathrm{mg} / \mathrm{dl}, \mathrm{p}<0,0001)$, $D$ dimerilor $(518,7 \pm 455,32$ vs. $1.314,22 \pm 1.347,54$ $\mu \mathrm{g} / \mathrm{ml}, \mathrm{p}<0,0001)$, troponinei $(1,8 \pm 4,02$ vs. $90,81 \pm 202,08, p<0,0001)$; raportul dintre numărul de neutrofile şi limfocite este mai mare în formele severe $(3,66 \pm 1,2$ vs. $6,21 \pm 4,21, p<0,0001)$. Dintre cei 33 de pacienţi cu forme severe, 16 (aproximativ $50 \%$ dintre aceștia, respectiv 5,33\% din cele 300 de cazuri) au decedat. Concluzii. Pacienţii cu forme severe de COVID-19 sunt mult mai în vârstă şi prezintă mai multe comorbidităţi (în special obezitate, suferinţe cardiovasculare, diabet zaharat sau malignităţi). Pentru detectarea precoce a formelor severe, medicii curanţi trebuie să deceleze dispneea, saturaţia scăzută în oxigen sau prezenţa ralurilor pulmonare, mai frecvent întâlnite în formele severe. Inflamaţia şi statusul procoagulant sunt semnificativ statistic mai bine exprimate la pacienţii cu forme severe. La nivelul lotului studiat, controlul glicemic a fost suboptimal pentru formele severe de boală. Chiar în condiţii de suport în compartimentul TI, jumătate dintre cei admişi cu forme severe (5,33\% din totalul cazurilor) au decedat
\end{abstract}

Cuvinte cheie: COVID-19, forme medii şi severe

\section{INTRODUCERE}

Pe 31 ianuarie 2019, Republica Populară Chineză raportează către Organizaţia Mondială a Sănătăţii (OMS) existenţa unui focar de pneumonii virale în oraşul Wuhan, provincia Hubei. Primul caz confirmat de infecţie cu noul coronavirus (denumit Severe Acute Respiratory Syndrome Coronavirus 2 SARS-CoV-2) a fost înregistrat de către OMS în data de 4 ianuarie 2020. Infecţia s-a răspândit ulterior pe tot globul, ceea ce a determinat Organizaţia Mondială a Sănătăţii (OMS) să o declare urgenţă de sănătate publică la nivel internaţional pe 30 ianuarie şi, ulterior, pandemie din 11 martie 2020 [1,2].

În România, primul caz a fost consemnat pe 21 februarie, iar la nivelul judeţului Dolj primul diagnostic a fost stabilit pe 6 martie 2020 .

Marea majoritate a cazurilor de COVID-19 sunt forme asimptomatice sau uşoare; cu toate acestea, 
formele severe sunt cele care necesită internare în secţiile de terapie intensivă, ridică probleme medicale şi logistice şi, în unele cazuri, conduc la decesul pacienţilor. Descrierea acestor forme şi semnalarea factorilor de risc (care pot prezenta unele variaţii, în funcţie de regiunea geografică luată în discuţie) pot fi utile medicilor din prima linie.

\section{OBIECTIVE}

Descrierea şi diferenţierea formelor medii şi severe de COVID-19 diagnosticate şi tratate în Clinica de Boli Infecţioase Craiova (din cadrul Spitalului de Boli Infecţioase şi Pneumoftiziologie „Victor Babeş").

\section{MATERIAL ŞI METODĂ}

Studiu retrospectiv (martie 2020 - iulie 2020) bazat pe informaţiile din foile de observaţie ale pacienţilor, introduse într-o bază de date Microsoft Excel. Analiza este una intermediară (primele 300 de cazuri internate) şi compară formele medii şi severe de COVID-19 din punct de vedere clinic şi biologic. Analiza statistică se bazează pe testele $\mathrm{Chi}^{2}$ (two tailes, cu corecţie Yates) şi t test (Student) nepereche, semnificaţia statistică fiind consemnată pentru $\mathrm{p}<0,05$.

Diagnosticul de COVID-19 a fost stabilit în urma unui rezultat pozitiv al unui test RT PCR pentru SARS CoV2.

Formele medii de boală sunt cele pentru care au fost consemnate modificări radiologice la nivel pulmonar, iar cele severe sunt cele care au necesitat internare în compartimentul de terapie intensivă cu cri- terii de sepsis, sindrom de detresă respiratorie al adultului (ARDS), alterarea statusului mental ori criterii de insuficienţă multiplă de organ (MSOF).

\section{REZULTATE}

Din totalul celor 300 de cazuri analizate, 56 pacienţi $(18,67 \%)$ au fost diagnosticaţi cu forme medii ale COVID-19, iar 33 (11\%) au prezentat forme severe de boală. Repartiţia lunară a cazurilor cazurilor este prezentată în figura 1 .

Vârsta medie a pacienţilor a fost de 49,5 $\pm 16,13$ ani în cazul formelor medii şi de $63 \pm 10,12$ ani pentru cele severe $(p<0,0001)$. În figura 2 este reprezentată distribuţia cazurilor pe grupe de vârstă. Doi copii au prezentat forme medii de boală, restul pacienţilor au fost adulţi (54 cu forme medii şi $33 \mathrm{cu}$ forme severe).

Repartiţia în funcţie de sexul pacienţilor este următoarea: pentru formele medii - 39 de bărbaţi şi 17 femei, iar pentru cele severe - 21 bărbaţi şi 12 femei, diferenţele neavând semnificaţie statistică.

Repartiţia în funcţie de mediul de provenienţă arată astfel: pentru formele medii, raportul urban rural este de 41/15, iar pentru formele severe de 25/8 (fără semnificaţie statistică).

În funcţie de judeţul de provenienţă, repartiţia bolnavilor este următoarea (forme medii/severe): Dolj (50/26), Mehedinţi (3/5), Olt (2/1) şi Gorj (1/1).

În tabelul 1 sunt redate sintetic datele privind antecedentele personale ale bolnavilor. Un număr semnificativ statistic mai mare de pacienţi diagnosticaţi cu obezitate, diabet zaharat, neoplazii sau suferinţe cardiovasculare (cu excepţia HTA) îi reprezintă pe cei cu forme severe de COVID-19.

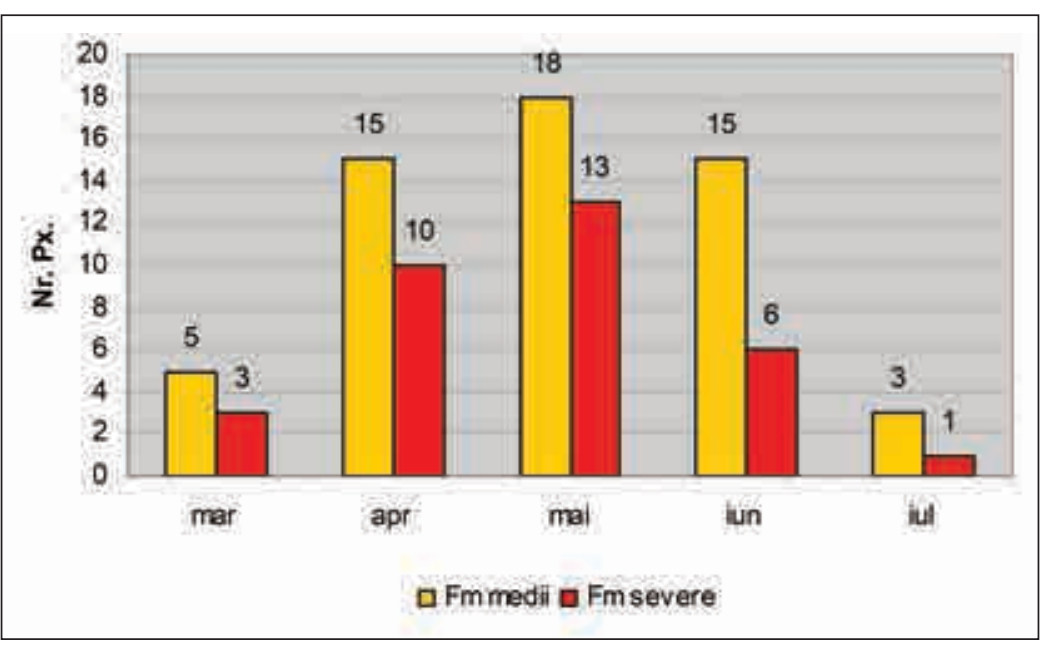

FIGURA 1. Repartiția lunară a cazurilor de COVID-19, forme medii şi severe, analiza din clinica craioveană 


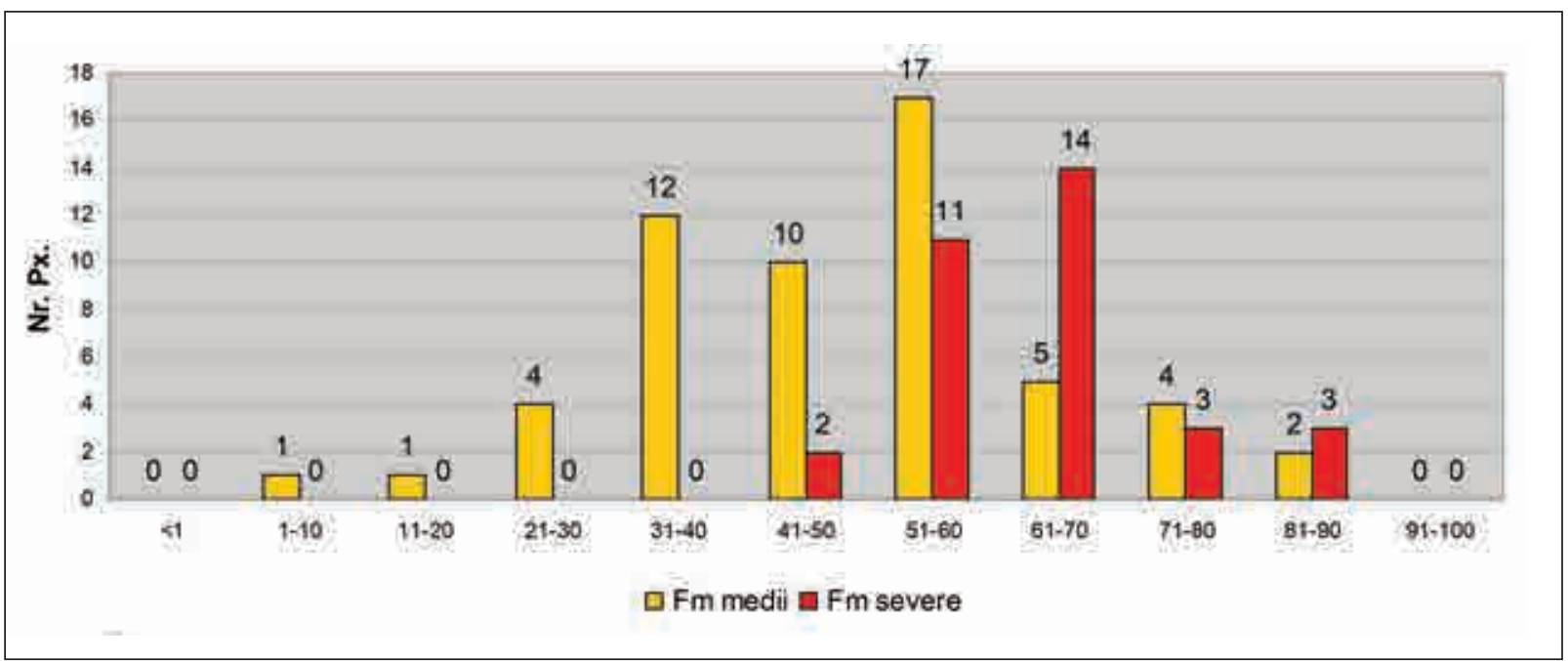

FIGURA 2. Repartiția cazurilor medii şi severe în funcție de categoria de vârstă a pacienților studiați

TABEL 1. Date privind antecedentele pacienților spitalizați în clinica craioveană cu forme medii şi severe de COVID-19; NS = nesemnificativ statistic

\begin{tabular}{|l|c|c|c|}
\hline & $\begin{array}{c}\text { Forme } \\
\text { medii }\end{array}$ & $\begin{array}{c}\text { Forme } \\
\text { severe }\end{array}$ & $\mathbf{p}$ \\
\hline HTA & 20 & 18 & NS \\
\hline Obezitate & $\mathbf{1 2}$ & $\mathbf{1 4}$ & $\mathbf{0 , 0 6}$ \\
\hline Alte boli cardiovasculare & $\mathbf{8}$ & $\mathbf{1 8}$ & $<\mathbf{0 , 0 0 0 1}$ \\
\hline Diabet zaharat & $\mathbf{9}$ & $\mathbf{1 5}$ & $\mathbf{0 , 0 0 5}$ \\
\hline Neoplazii & $\mathbf{2}$ & $\mathbf{7}$ & $\mathbf{0 , 0 2}$ \\
\hline Boală cronică renală & 0 & 0 & NS \\
\hline Astm bronşic & 2 & 2 & NS \\
\hline Hepatită cronică B & 1 & 0 & NS \\
\hline BPOC & 0 & 2 & NS \\
\hline Sarcină & 0 & 0 & NS \\
\hline TBC & 0 & 0 & NS \\
\hline HIV & 0 & 0 & NS \\
\hline $\begin{array}{l}\text { Insuficiență respiratorie } \\
\text { cronică }\end{array}$ & 1 & 2 & NS \\
\hline
\end{tabular}

În tabelul 2 sunt prezentate acuzele pacienţilor la internare. Se observă că cele mai frecvente acuze au fost cele care ţin de căilor aeriene inferioare şi de ţesutul pulmonar (tuse, dispnee - diferenţă cu semnificaţie statistică - şi expectoraţie), alături de simptomatologia de tip general (febră, frisoane, astenie fizică).

TABEL 2. Comparație între acuzele la internare ale pacienților diagnosticați în clinica craioveană cu COVID-19, forme medii şi severe; CRS = căi respiratorii superioare, NS = nesemnificativ statistic

\begin{tabular}{|l|c|c|c|}
\hline Simptome & $\begin{array}{c}\text { Forme } \\
\text { medii }\end{array}$ & $\begin{array}{c}\text { Forme } \\
\text { severe }\end{array}$ & $\mathbf{p}$ \\
\hline Febră & 34 & 26 & NS \\
\hline Frisoane & 18 & 15 & NS \\
\hline Astenie & 13 & 14 & NS \\
\hline Mialgii & 7 & 1 & NS \\
\hline Cefalee & 8 & 2 & NS \\
\hline Subfebră & 6 & 3 & NS \\
\hline
\end{tabular}

\begin{tabular}{|l|c|c|c|}
\hline Simptome & $\begin{array}{c}\text { Forme } \\
\text { medii }\end{array}$ & $\begin{array}{c}\text { Forme } \\
\text { severe }\end{array}$ & $\mathbf{p}$ \\
\hline Artralgii & 2 & 0 & NS \\
\hline Oculalgii & 3 & 1 & NS \\
\hline Disfagie & 11 & 2 & NS \\
\hline Rinoree & 0 & 2 & NS \\
\hline Obstrucția CRS & 1 & 0 & NS \\
\hline Otalgie & 0 & 0 & NS \\
\hline Disfonie & 1 & 1 & NS \\
\hline Tuse & 44 & 27 & NS \\
\hline Dispnee & $\mathbf{1 4}$ & $\mathbf{2 4}$ & $<0,0001$ \\
\hline Expectorație & 12 & 8 & NS \\
\hline Durere toracică & 8 & 0 & NS \\
\hline Cianoză & 3 & 0 & NS \\
\hline Anosmie & 8 & 0 & NS \\
\hline Ageuzie & 5 & 0 & NS \\
\hline Inapetență & 7 & 5 & NS \\
\hline Diaree & 3 & 1 & NS \\
\hline Grețuri, vărsături & 3 & 2 & NS \\
\hline Dureri abdominale & 1 & 2 & NS \\
\hline
\end{tabular}

În tabelul 3 sunt notate datele clinice depistate la examenul obiectiv al pacienţilor, diferenţe semnificativ statistic fiind înregistrate pentru numărul de pacienţi depistaţi cu raluri pulmonare, cu saturaţii ale oxigenului sub $90 \%$, intubaţi sau comatoşi.

Analiza datelor de laborator ale pacienţilor studiaţi a relevat următoarele diferenţe cu semnificaţie statistică (forme medii vs. severe): hemoglobina (g/dl) $12,56 \pm 1,46$ vs. $12,97 \pm 2,29, \mathrm{p}<0,0001$; numărul de leucocite $\left(/ \mathrm{mm}^{3}\right) \quad 6.176,07 \pm 2.512,05$ vs. $8.666,67 \pm 4.565,88, \mathrm{p}=0,001$; viteza de sedimentare a hematiilor ( $\mathrm{mm} / 1 \mathrm{~h}) 43,05 \pm 28,09$ vs. $71,18 \pm 30,8$, $\mathrm{p}<0,0001$; proteina $\mathrm{C}$ reactivă $(\mathrm{mg} / \mathrm{l}) 29,62 \pm 19,81$ $(\mathrm{n}=23)$ vs. $43,46 \pm 18,01(\mathrm{n}=24), \mathrm{p}=0,01$; lactat seric $(\mathrm{mEq} / \mathrm{l}) 1,19 \pm 0,91$ vs. $3,47 \pm 3,84, \mathrm{p}=0,006$; 
TABEL 3. Comparație între datele clinice depistate prin examenul obiectiv al pacienților diagnosticați în clinica craioveană cu COVID-19, forme medii şi severe; $N S=$ nesemnificativ statistic; $P x=$ pacienți, $A V=$ alura ventriculară, TAS = tensiunea arterială sistolică, $T A D=$ tensiunea arterială diastolică

\begin{tabular}{|l|c|c|c|}
\hline & Forme medii & $\begin{array}{c}\text { Forme } \\
\text { severe }\end{array}$ & $\mathbf{p}$ \\
\hline Febrili & 19,00 & 15,00 & NS \\
\hline Subfebrili & 11,00 & 5,00 & NS \\
\hline Conjunctivită & 0,00 & 0,00 & NS \\
\hline Raluri bronşice & 1,00 & 4,00 & NS \\
\hline Subcrepitante & 4,00 & 6,00 & NS \\
\hline Crepitante & 3,00 & 3,00 & NS \\
\hline Raluri (total) & $\mathbf{8 , 0 0}$ & $\mathbf{1 3 , 0 0}$ & $\mathbf{0 , 0 1}$ \\
\hline Px cu SaO2 <90 & $\mathbf{0 , 0 0}$ & $\mathbf{2 0 , 0 0}$ & $<\mathbf{0 , 0 0 0 1}$ \\
\hline Intubați & $\mathbf{0 , 0 0}$ & $\mathbf{1 4 , 0 0}$ & $<\mathbf{0 , 0 0 0 1}$ \\
\hline AV medie & 91,20 & 89,09 & NS \\
\hline AV stdev & 18,70 & 18,36 & NS \\
\hline TAS medie & 129,00 & 127,16 & NS \\
\hline TAS stdev & 21,74 & 29,29 & NS \\
\hline Px cu TAS > 140 & $\mathbf{2 , 0 0}$ & $\mathbf{9 , 0 0}$ & $\mathbf{0 , 0 1}$ \\
\hline Px cu TAS < 90 & 0,00 & 1,00 & NS \\
\hline TAD medie & 79,80 & 71,94 & NS \\
\hline TAD stdev & 18,69 & 18,39 & NS \\
\hline Px cu TAD > 90 & 1,00 & 3,00 & NS \\
\hline Px cu TAD < 60 & 0,00 & 2,00 & NS \\
\hline Diaree & 4,00 & 1,00 & NS \\
\hline Constipație & 0,00 & 0,00 & NS \\
\hline Adenopatii & 0,00 & 0,00 & NS \\
\hline Hepatomegalie & 1,00 & 4,00 & NS \\
\hline Splenomegalie & 0,00 & 1,00 & NS \\
\hline Oligurie & 1,00 & 4,00 & NS \\
\hline Anurie & 0,00 & 1,00 & NS \\
\hline Redoare de ceafă & 0,00 & 0,00 & NS \\
\hline Comă & $\mathbf{0 , 0 0}$ & $\mathbf{5 , 0 0}$ & $\mathbf{0 , 0 1}$ \\
\hline
\end{tabular}

uree (mg/dl) 27,55 1,77 vs. $88,97 \pm 74,53, \mathrm{p}<0,0001$; GPT (u/l) 30,27 $\pm 8,65$ vs. $15,85 \pm 0,49, \mathrm{p}<0,0001$; glicemie $(\mathrm{mg} / \mathrm{dl}) \quad 112,5 \pm 25,01$ vs. $304,45 \pm 273,58$, $\mathrm{p}<0,0001 ; \mathrm{D}$ dimeri $(\mathrm{mg} / \mathrm{ml}) 518,7 \pm 455,32(\mathrm{n}=21)$ vs. $1.314,22 \pm 1.347,54(\mathrm{n}=23), \mathrm{p}=0,01$; troponina ((mg/l) $1,8 \pm 4,02(\mathrm{n}=6)$ vs. 90,81 $\pm 202,08(\mathrm{n}=5)$, $\mathrm{p}<0,0001$. În schimb, nu au fost obţinute diferenţe cu semnificaţie statistică pentru: numărul de trombocite $\left(/ \mathrm{mm}^{3}\right) 237646,43 \pm 103615,39$ vs. $249687,88 \pm$ 128903,78 ; creatinină (mg/dl) $1,21 \pm 0,28$ vs. $1,09 \pm$ 0,03 ; procalcitonină $(\mathrm{ng} / \mathrm{ml}) 0,11 \pm 0,02(\mathrm{n}=21)$ vs. $0,92 \pm 2,43(\mathrm{n}=20)$. Raportul dintre numărului de neutrofile şi, respectiv, limfocite (NLR) este de $3,66 \pm 1,2$ pentru formele medii, respectiv $6,21 \pm 4,21$ pentru cele severe $(\mathrm{p}<0,0001)$. Pentru lotul studiat, raportul dintre numărul de trombocite şi cel al limfocitelor (PLR) este de 249,76 $\pm 461,05$, respectiv $217,24 \pm 1$ 12,16, iar cel dintre numărul de limfocite şi valoarea proteinei C reactive (LCR) de 49,51 $\pm 61,09$, respectiv 74,43 $\pm 77,8$; comparativ, pentru cele două rapoarte nu se atinge pragul de semnificaţie statistică.

În tabelul 4 sunt redate comparativ informaţiile imagistice pulmonare pentru pacienţii diagnosticaţi cu COVID-19 incluşi în studiu.

TABEL 4. Aspecte radiologice la pacienții diagnosticați în clinica craioveană cu COVID-19, forme medii şi severe;

$N S=$ nesemnificativ statistic

\begin{tabular}{|l|c|c|c|}
\hline & $\begin{array}{c}\text { Forme } \\
\text { medii }\end{array}$ & $\begin{array}{c}\text { Forme } \\
\text { severe }\end{array}$ & $\mathbf{p}$ \\
\hline Aspect de pneumonie alveolară & 25 & 18 & NS \\
\hline Aspect interstițial & $\mathbf{2 0}$ & $\mathbf{3}$ & $\mathbf{0 . 0 1}$ \\
\hline Aspect normal & 10 & 2 & NS \\
\hline Aspect de bronhopneumonie & $\mathbf{0}$ & $\mathbf{6}$ & $\mathbf{0 . 0 0 4}$ \\
\hline Aspect de „geam mat“ & 1 & 3 & NS \\
\hline Aspect lichidian pleural & 0 & 0 & NS \\
\hline Abcese & 0 & 1 & NS \\
\hline
\end{tabular}

Media zilelor de spitalizare pentru cele două forme de boală (medii vs. severe) a fost de 14,76 $\pm 5,74$ zile vs. 14,09 $\pm 8,29$ zile (nesemnificativ statistic). În tabelul 5 sunt prezentate comparativ alte date cu privire la evoluţia bolnavilor din clinica craioveană.

TABEL 5. Date evolutive înregistrate la pacienții craioveni diagnosticați cu COVID-19 forme medii sau severe

\begin{tabular}{|l|c|c|c|}
\hline & $\begin{array}{c}\text { Forme } \\
\text { medii }\end{array}$ & $\begin{array}{c}\text { Forme } \\
\text { severe }\end{array}$ & $\mathbf{p}$ \\
\hline Zile de febră în evoluție & & & \\
\hline media & 2,13 & 2,71 & NS \\
\hline deviația standard & 1,68 & 2,21 & \\
\hline Zile de simptomatologie & & & \\
\hline media & $\mathbf{6 , 6 0}$ & $\mathbf{1 2 , 8 8}$ & $<\mathbf{0 , 0 0 0 1}$ \\
\hline deviația standard & 4,51 & 8,09 & \\
\hline Px admişi în TI & $\mathbf{8}$ & $\mathbf{3 3}$ & $<\mathbf{0 , 0 0 0 1}$ \\
\hline Ventilați mecanic & $\mathbf{2}$ & $\mathbf{1 9}$ & $<\mathbf{0 , 0 0 0 1}$ \\
\hline CPAP / O2 pe mască & $\mathbf{6}$ & $\mathbf{1 3}$ & $\mathbf{0 , 0 0 3}$ \\
\hline Zile TI & & & \\
\hline media & 10,55 & 13 & NS \\
\hline deviația standard & 13,40 & 7,06 & \\
\hline
\end{tabular}

Rezultatul spitalizării bolnavilor incluşi în studiu este arătat în tabelul 6.

TABEL 6. Rezultatul final al spitalizării pacienților craioveni diagnosticați cu COVID-19, forme medii sau severe; $N S=$ nesemnificativ statistic

\begin{tabular}{|l|c|c|c|}
\hline & $\begin{array}{c}\text { Forme } \\
\text { medii }\end{array}$ & $\begin{array}{c}\text { Forme } \\
\text { severe }\end{array}$ & $\mathbf{p}$ \\
\hline Ameliorat & 5 & 1 & NS \\
\hline Vindecat & $\mathbf{5 0}$ & $\mathbf{1 4}$ & $<0,0001$ \\
\hline Agravat şi transferat & 1 & 2 & NS \\
\hline Decedat & $\mathbf{0}$ & $\mathbf{1 6}$ & $<0,0001$ \\
\hline
\end{tabular}




\section{DISCUȚII}

Vârsta pacienţilor pare să fie un factor important care determină apariţia formelor severe de boală. Din datele obţinute de noi, se observă o diferenţă a vârstei medii de 13 ani între cei cu forme medii versus cei cu forme severe, ceea ce corespunde cu datele din literatura de specialitate [3-7]. De remarcat că nu am înregistrat forme severe de boală la pacienţi pediatrici, aceştia reprezentând însă o minoritate în cadrul pacienţilor trataţi în cadrul Spitalului de Boli Infecţioase şi Pneumoftiziologie din Craiova.

În concordanţă cu datele disponibile din literatura medicală $[3,4,6,7]$, am observat o preponderenţă a sexului masculin pentru formele medii (raport $\mathrm{M} / \mathrm{F}=2,29$ ) sau severe (raport $\mathrm{M} / \mathrm{F}=1,75$ ) de COVID-19, dar fără semnificaţie statistică (probabil din cauza numărului mic de bolnavi incluşi în studiu).

Similar cu datele raportate de alţi cercetători $[3,4,6,8,9]$, pacienţii trataţi în clinica craioveană aveau multiple comorbidităţi, între cele două forme de boală luate în considerare existând diferenţe semnificative statistic pentru obezitate, suferinţe cardiovasculare, diabet zaharat sau neoplazii diverse. La examenul obiectiv, mai mulţi pacienţi cu forme severe aveau valori crescute ale tensiunii arteriale sistolice comparativ cu cei cu forme medii (2 vs. 9, $p=0,01)$. Aceste suferinţe sunt însă printre cele mai frecvente cauze de morbiditate şi mortalitate la nivel mondial [10], iar asocierea acestora cu COVID-19 pare să contribuie semnificativ la agravarea bolii şi decesul pacienţilor [11-14].

Dintre simptomele sugestive pentru forma severă de COVID-19, se remarcă dispneea, aceasta impunând o monitorizare mai atentă din partea medicului curant, pentru a surprinde momentul în care este nevoie de transferul pacientului în sectorul de terapie intensivă (TI). De asemenea, semnificativ statistic, mai mulţi pacienţi cu formă severă au prezentat raluri la auscultaţia pulmonară, fără să existe însă diferenţe semnificative în ceea ce priveşte tipul acestora.

Datele de laborator ale lotului studiat arată o serie de diferenţe cu semnificaţie statistică, cele mai im- portante fiind cele ce relevă un nivel mai mare al inflamaţiei şi un status procoagulant crescut al pacienţilor cu forme severe, informaţiile fiind în concordanţă cu cele relevate de literatura medicală. Pentru pacienţii cu forme severe din lotul studiat controlul glicemiei a fost unul suboptimal. Dintre markerii surogat pentru gravitatea formelor, uşor de utilizat la patul bolnavului, se remarcă NLR, PLR şi LCR $[15,16]$; pe lotul studiat, au fost observate diferenţe semnificative din punct de vedere statistic pentru NLR, dar nu şi pentru PLR sau LCR. Spre deosebire de datele altor autori, PLR a înregistrat valori mai mari la pacienţii cu forme medii; trebuie însă remarcat faptul că studiul nostru include un număr relativ mic de pacienţi.

Semnificativ statistic, aspectul radiologic de tip bronhopneumonic se asociază cu formele severe de boală; repetarea examenului, cu scopul de a surprinde cât mai devreme acest aspect, poate fi utilă medicului curant.

$\mathrm{Cu}$ toate eforturile medicale depuse, aproape jumătate dintre cei cu forme severe $(5,33 \%$ din totalul pacienţilor analizaţi) au decedat. Procentul global este în concordanţă cu datele prezentate în literatura aferentă COVID-19 [3-9].

\section{CONCLUZII}

Pacienţii cu forme severe de COVID-19 sunt mult mai în vârstă şi prezintă mai multe comorbidităţi (în special obezitate, suferinţe cardiovasculare, diabet zaharat sau malignităţi) comparativ cu cei cu forme medii de boală. Pentru detectarea precoce a formelor severe, medicii curanţi trebuie să deceleze dispneea, saturaţia scăzută în oxigen sau prezenţa ralurilor pulmonare, mai frecvent întâlnite în formele severe. Inflamaţia şi statusul procoagulant sunt semnificativ statistic mai bine exprimate la pacienţii cu forme severe. La nivelul lotului studiat, controlul glicemic a fost suboptimal pentru formele severe de boală. Chiar în condiţii de suport în compartimentul TI, aproape jumătate dintre cei admişi cu forme severe $(5,33 \%$ din totalul cazurilor) au decedat.

Conflict of interest: none declared Financial support: none declared

\section{BIBLIOGRAFIE}

1. WHO Coronavirus Diseases (COVID-19) dashboard, available at: COVID-19.who.int.

2. Timeline of WHO's response to COVID-19, available at: who.int/ news-room/detail/29-06-2020-covidtimeline.

3. Chen $\mathrm{T}, \mathrm{Wu} \mathrm{D}, \mathrm{Chen} \mathrm{H}$ et al. Clinical characteristics of 113 deceased patients with coronavirus disease 2019: retrospective study. BMJ. 2020;368:m1091.

4. Zhang B, Zhou X, Qu Y et al. Clinical characteristics of 82 cases of death from COVID-19. PIoS ONE. 2020;15(7):e0235458. 
5. Xie P, Ma W, Tang H, Liu D. Severe COVID-19: a review of recent progress with a look toward the future. Front Public Health. 2020; 8:189.

6. Richardson S, Hirsch JS, Narasimhan M et al. Presenting characteristics, comorbidities and outcome among 5700 patients hospitalized with COVID-19 in the New York city area. JAMA. 2020; 323(20):2052-2059.

7. King's Critical Care - Evidence summary clinical management of COVID-19, available at: scts.org/wp-content/uploads/2020/03/01Kings-Critical-Care-COVID19-Evidence-Summary-9th-March-2020. pdf.

8. Huang C, Wang X, Li X et al. Clinical features of patients infected with 2019 novel coronavirus in Wuhan, China. Lancet. 2020; 395:497-506.

9. Guan W, Ni Z, Hu Y et al Clinical features of coronavirus diseases 2019 in China. NEJM. 2020;382:1708-1720.

10. Global Health Observatory (GHO) data, Top 10 causes of death, 2016, available at: who.int/gho/mortality_burden_disease/causes_ death/top_10/en/.
11. Yanai H. Adiposity is the crucial enhancer of COVID-19. Cardiol Res. 2020;11(5):353-354.

12. Yanai $\mathrm{H}$. A significance of high prevalence of diabetes and hypertension in severe COVID-19 patients. J Clin Med Res. 2020; 12(6):389-392.

13. Costa de Luceno TM, Fernandes sa Silva Santos A, Regina de Lima $B$ et al. Mechanism of inflammatory response in associated comorbidities in COVID-19. Diabetes Metab Syndr. 2020; 14(4):597-600.

14. Sanchis-Gomar F, Lavie CJ, Mehra MR et al. Obesity and outcome in COVID-19: when an epidemic and pandemic collide. Mayo Clin Proc. 2020;95)7):1445-1453.

15. Chan AS, Rout A. Use of neutrophil-to-lymphocyte and platelet-tolymphocyte ratios in COVID-19. J Clin Med Res. 2020; 12(7):448-453.

16. Ullah W, Basyal B, Tariq $S$ et al. Lymphocyte-to-C reactive protein ratio: a novel predictor of adverse outcome in COVID-19. J Clin Med Res. 2020;12(7):415-422. 